\title{
Venant Cauchy in memoriam
}

\author{
YVON GAUTHIER Université de Montréal
}

Venant Cauchy (18 mai 1924-30 mars 2008), professeur émérite au département de philosophie de l'Université de Montréal, est disparu à la veille de ses 84 ans. Sa carrière à l'Université de Montréal a débuté en 1957 après un séjour de quelques années dans les universités américaines, dont l'Université Fordham à New York. Spécialiste de la philosophie grecque, d'Aristote à Pyrrhon, il a publié des travaux sur la difficile question du syllogisme modal dans la logique aristotélicienne. Son enseignement couvrait toute l'étendue de l'histoire de la philosophie, des Grecs aux philosophes américains contemporains comme C. Hartshorne et A. N. Whitehead, comme en font foi les nombreux articles qu'il a publiés dans The New Scholasticism sur les concepts philosophiques et les grands auteurs de la tradition philosophique.

Père de treize enfants, il a voulu élargir la famille philosophique québécoise en invitant chez nous les philosophes de partout. Ainsi a-t-il organisé en 1971 le XV ${ }^{\mathrm{e}}$ Congrès de l'Association des sociétés de langue française et il a présidé le $\mathrm{XVII}^{\mathrm{e}}$ Congrès mondial de philosophie en 1983 où plus de 3000 philosophes du monde entier ont été invités. Toujours avec sa fidèle collaboratrice, son épouse Denyse, il a organisé en 1992 le II ${ }^{\mathrm{e}}$ Congrès mondial sur la violence et la coexistence humaine qui a réuni 1500 chercheurs de divers horizons, travailleurs sociaux, économistes, psychologues et philosophes œuvrant pour la paix dans le monde. Dans le même esprit que son engagement pour la coexistence pacifique, il a participé au Groupe de Vezelay devenu par la suite l'Alliance pour un monde responsable et solidaire.

Venant Cauchy n'a pas négligé pour autant la scène philosophique locale, puisqu'il a été président fondateur de la Société de philosophie du Québec. Il avait été auparavant cofondateur avec H.M. Estall et rédacteur francophone jusqu'en 1974 de la première revue canadienne de philosophie Dialogue, organe officiel de l'Association canadienne de philosophie dont il

Dialogue XLVII (2008), 419-20

(C) 2008 Canadian Philosophical Association/Association canadienne de philosophie 
sera président en 1978 et membre honoraire à vie. Philosophe universitaire, mais éducateur au sens le plus large du terme, le projet de l'enseignement de la philosophie pour enfants lui tenait à cœur.

Ses activités d'animateur de la vie philosophique ne se comptent plus. Encore récemment il participait au dernier congrès de l'Association des sociétés de philosophie de langue française à Budapest. Membre de nombreux comités internationaux pour la promotion de la philosophie, il a multiplié les déplacements à l'étranger tout au long de sa carrière, mais il est toujours demeuré fidèle au Québec où sont nés et ont vécu ses parents. Né à North Bay, il a fait ses études postsecondaires à l'Université de Montréal où il a obtenu un doctorat en philosophie à l'âge de 23 ans. Il a été directeur du département de philosophie de 1970 à 1974 et a été nommé professeur émérite en 1993.

Sans doute l'un des témoignages les plus éloquents du rayonnement de l'activité philosophique de Venant Cauchy demeure le recueil de Mélanges en son honneur publié en 1993 sous le titre Le dialogue humaniste aux Presses de l'Université de Montréal. C'est là un titre qui traduit bien le sens d'une carrière dédiée au dialogue entre les cultures dans le respect des traditions et des héritages philosophiques singuliers. Dans ce recueil, des philosophes québécois et canadiens, nord-américains, sud-américains et européens ont joint leurs voix pour rendre hommage au grand rassembleur qu'a été Venant Cauchy. D'autres honneurs se sont ajoutés tout au long de sa carrière, comme la médaille Aristote du Ministère des affaires culturelles de la Grèce en 1978 et un doctorat honoris causa de l'Université d'Athènes en 1987.

En liaison harmonieuse avec son engagement dans la communauté philosophique internationale, Venant Cauchy a toujours été un ardent nationaliste et un défenseur passionné de l'indépendance du Québec qu'il voyait comme une garantie de l'épanouissement culturel. Ses vœux d'un Québec libre et ouvert au monde qu'il a exprimés à la toute fin de sa vie sont sans doute l'écho de l'universalisme philosophique qu'il prônait; pour lui, l'universel s'enracinait dans la proximité où le dialogue trouvait son lieu de naissance.

Le texte publié dans ce même numéro est la dernière conférence de Venant Cauchy au congrès de l'Association des sociétés de philosophie de langue française à Budapest en 2006. Ce texte rend parfaitement compte à mon sens d'une carrière philosophique qui a été consacrée pour une grande part au dialogue philosophique et à l'interaction de toutes les cultures dans un esprit d'ouverture et de coopération entre partenaires égaux. Cet humaniste généreux ne se privait pas cependant de vives dénonciations lorsqu'il s'agissait de stigmatiser les usurpations d'une raison politique ou économique assujettie aux objectifs du profit et à l'impérialisme des pouvoirs qui cherchent à substituer la mondialisation des produits à la liberté de tous les producteurs de valeurs et de biens culturels. La philosophie pour l'humaniste Venant Cauchy avait justement pour mission la réconciliation des diversités culturelles et des identités personnelles dans un idéal universel de liberté et de justice sociale par-delà l'injustice économique et la déraison politique. 